Supporting Information for

\title{
In-Situ Enrichment of Phosphopeptides on MALDI Plates Functionalized by Reactive Landing of Zirconium(IV)-n-Propoxide Ions
}

Grady R. Blacken, ${ }^{\boldsymbol{a}}$ Michael Volný, ${ }^{\boldsymbol{a}}$ Tomáš Vaisar, ${ }^{\boldsymbol{b}}$ Martin Sadílek, ${ }^{\boldsymbol{a}}$ and František Tureček ${ }^{\boldsymbol{a}_{*}}$ Departments of Chemistry and Medicine, University of Washington, Box 351700, Seattle, WA $98195-1700$

Manuscript submitted to Analytical Chemistry, April 2007. Figures S1-S7.

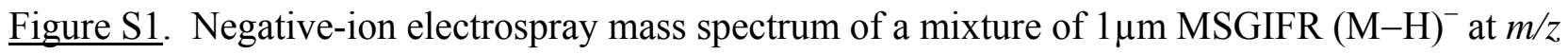
708) and $1 \mu \mathrm{M}$ MpSGIFR $(\mathrm{M}-\mathrm{H})^{-}$at $m / z 788$ that was enriched for phosphopeptide on Zr-oxide surface prepared by reactive landing of $\mathrm{Zr}(\mathrm{IV})-n$-propoxide on stainless steel. The enriched sample was eluted consecutively with (a) $100 \mathrm{mM} \mathrm{NH}_{4} \mathrm{OH}$, (b) $500 \mathrm{mM} \mathrm{NH}_{4} \mathrm{OH}$ and (c) $1 \mathrm{M} \mathrm{NH}_{4} \mathrm{OH}$. The phosphopeptide with an oxidized methionine residue is indicated by an asterisk.

Figure S2. Negative ion ESI mass spectrum of $1 \mu \mathrm{M}$ MpSGIFR and $1 \mu \mathrm{M}$ MSGIFR in $1 \mathrm{M} \mathrm{NH}_{4} \mathrm{OH}$ measured on a Bruker Esquire ion-trap mass spectrometer.

Figure S3. Top: MALDI-MS analysis of $10 \mu \mathrm{M}$ MSGIFR $\left(\mathrm{MH}^{+} \mathrm{m} / \mathrm{z} 710.3\right), 100 \mathrm{nM}$ MpSGIFR $\left(\mathrm{MH}^{+} \mathrm{m} / \mathrm{z}\right.$ 790.3), $100 \mathrm{nM}$ pYWQAFR $\left(\mathrm{MH}^{+} \mathrm{m} / \mathrm{z}\right.$ 950.3) and $100 \mathrm{nM}$ NQLLpTPLR $\left(\mathrm{MH}^{+} \mathrm{m} / \mathrm{z}\right.$ 1033.5). Enrichment of the same peptide mixture on $\mathrm{Zr}$-oxide prepared by reactive landing of $\mathrm{Zr}$ (IV)-n-propoxide. Peptides with an oxidized Met or Trp are denoted by an asterisk. 
Figure S4. Top: MALDI-MS analysis of $10 \mu \mathrm{M}$ MSGIFR $\left(\mathrm{MH}^{+} \mathrm{m} / \mathrm{z}\right.$ 710.3), $10 \mu \mathrm{M}$ MpSGIFR $\left(\mathrm{MH}^{+} \mathrm{m} / \mathrm{z}\right.$ 790.3), $10 \mu \mathrm{M}$ pYWQAFR $\left(\mathrm{MH}^{+} \mathrm{m} / \mathrm{z}\right.$ 950.3) and $10 \mu \mathrm{M}$ NQLLpTPLR $\left(\mathrm{MH}^{+} \mathrm{m} / \mathrm{z}\right.$ 1033.5). Bottom: Enrichment of the same peptide mixture on $\mathrm{Zr}$-oxide prepared by reactive landing of $\mathrm{Zr}(\mathrm{IV})-n$-propoxide. Peptides with an oxidized Met or Trp are denoted by asterisks.

Figure S5. (a) Control enrichment of $\alpha$-casein phosphopeptides on plasma oxidized stainless steel at a surface concentration of 1 pmol per MALDI spot. (b) Blank analysis from enrichment of $\alpha$-casein phosphopeptides on plasma oxidized stainless steel. Peptide was not applied to the blank spot. Phosphopeptides are denoted by asterisks.

Figure S6. Enrichment of $10 \mu \mathrm{M}$ MSGIFR, $1 \mu \mathrm{M}$ MpSGIFR, $1 \mu \mathrm{M}$ pYWQAFR and $1 \mu \mathrm{M}$ NQLLpTPLR on plasma-oxidized Zr metal. Detected by positive-ion MALDI-MS off the surface used for enrichment assay. Phosphopeptides with an oxidized Met or Trp are denoted by an asterisk.

Figure S7. Enrichment of 1 pmol of an $\alpha$-casein tryptic digest on plasma oxidized Zr metal. Detected by positive-ion MALDI-MS off the surface used for enrichment assay. Phosphopeptides are denoted by asterisks. 

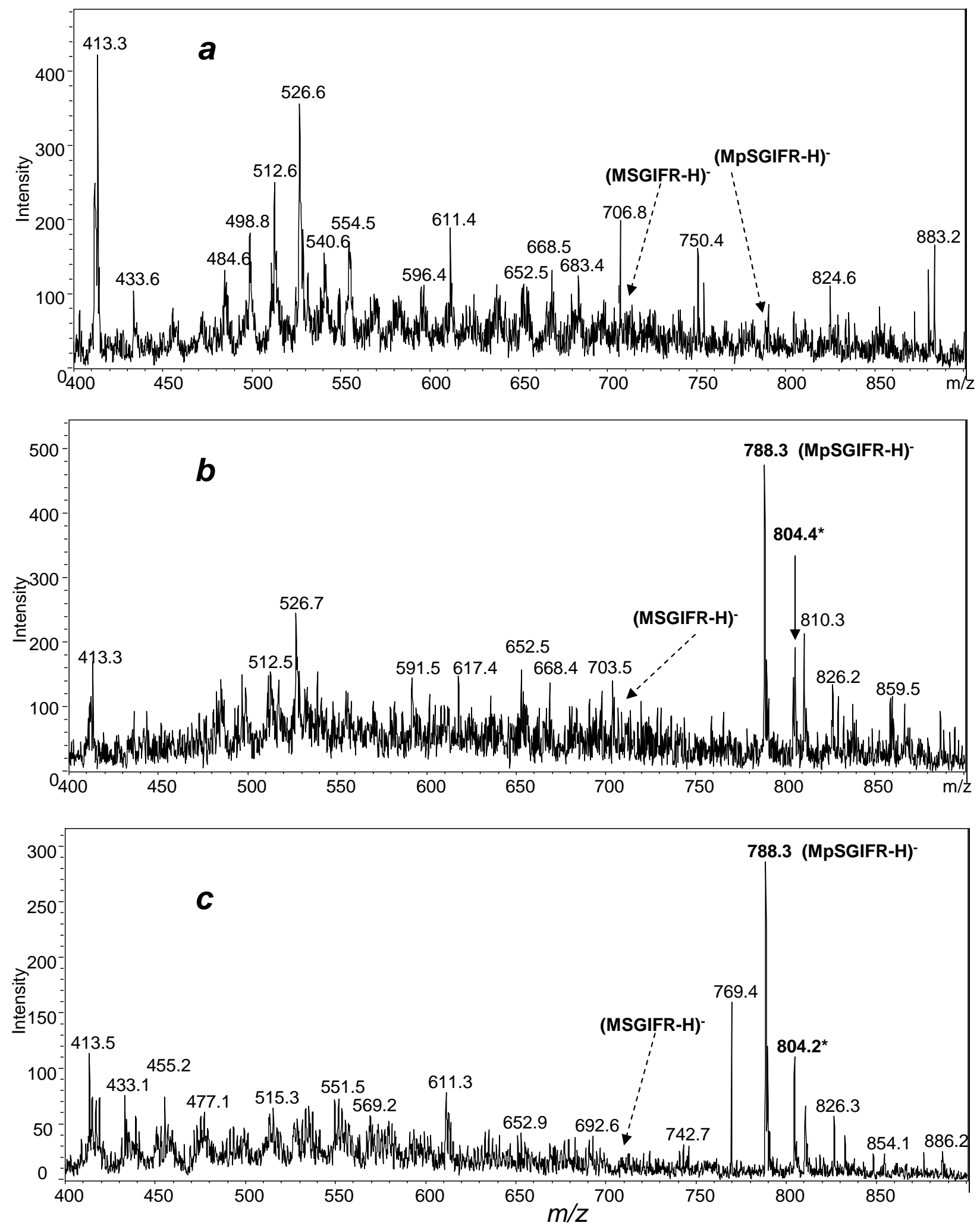

Figure S1. 


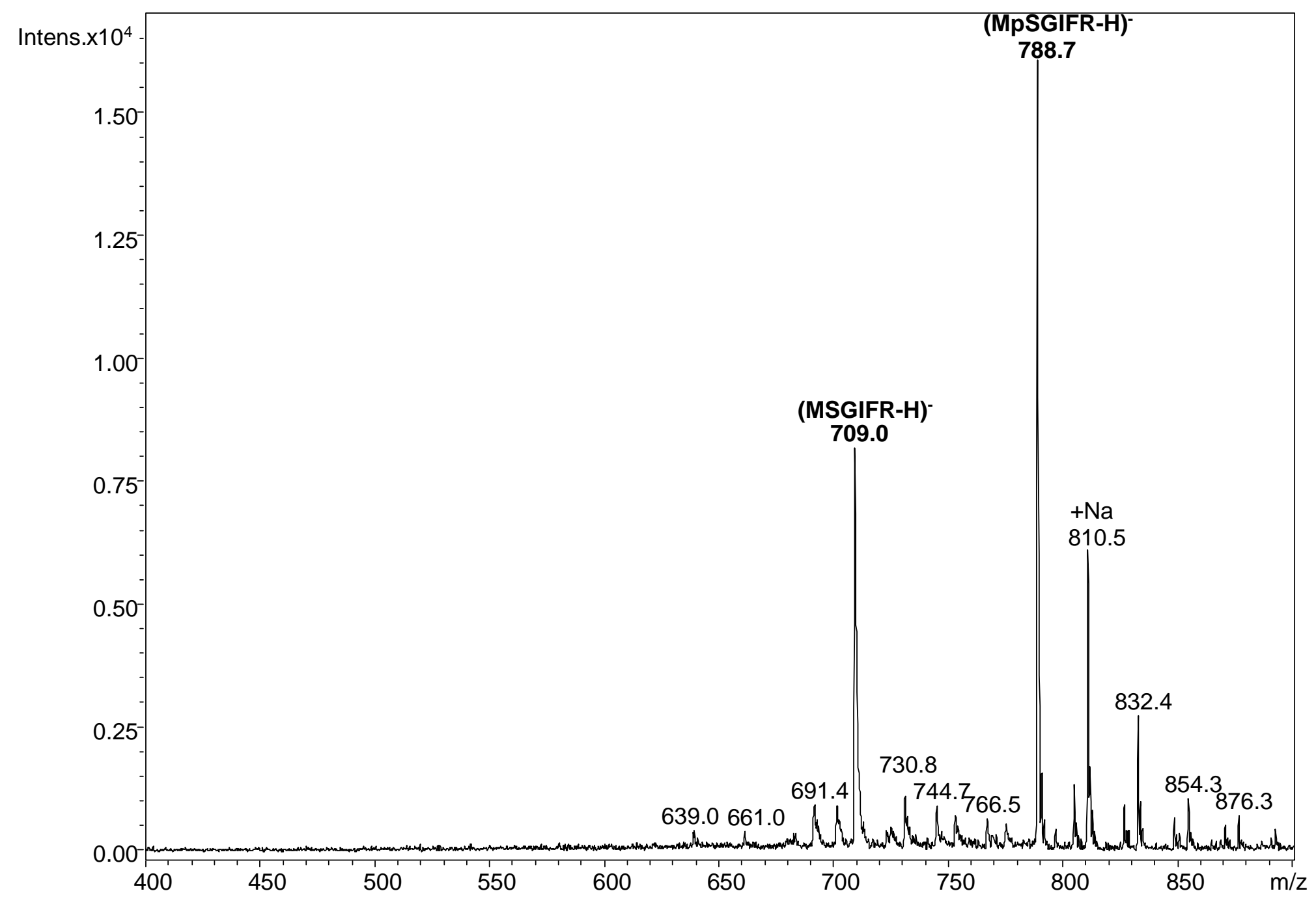

Figure S2. 


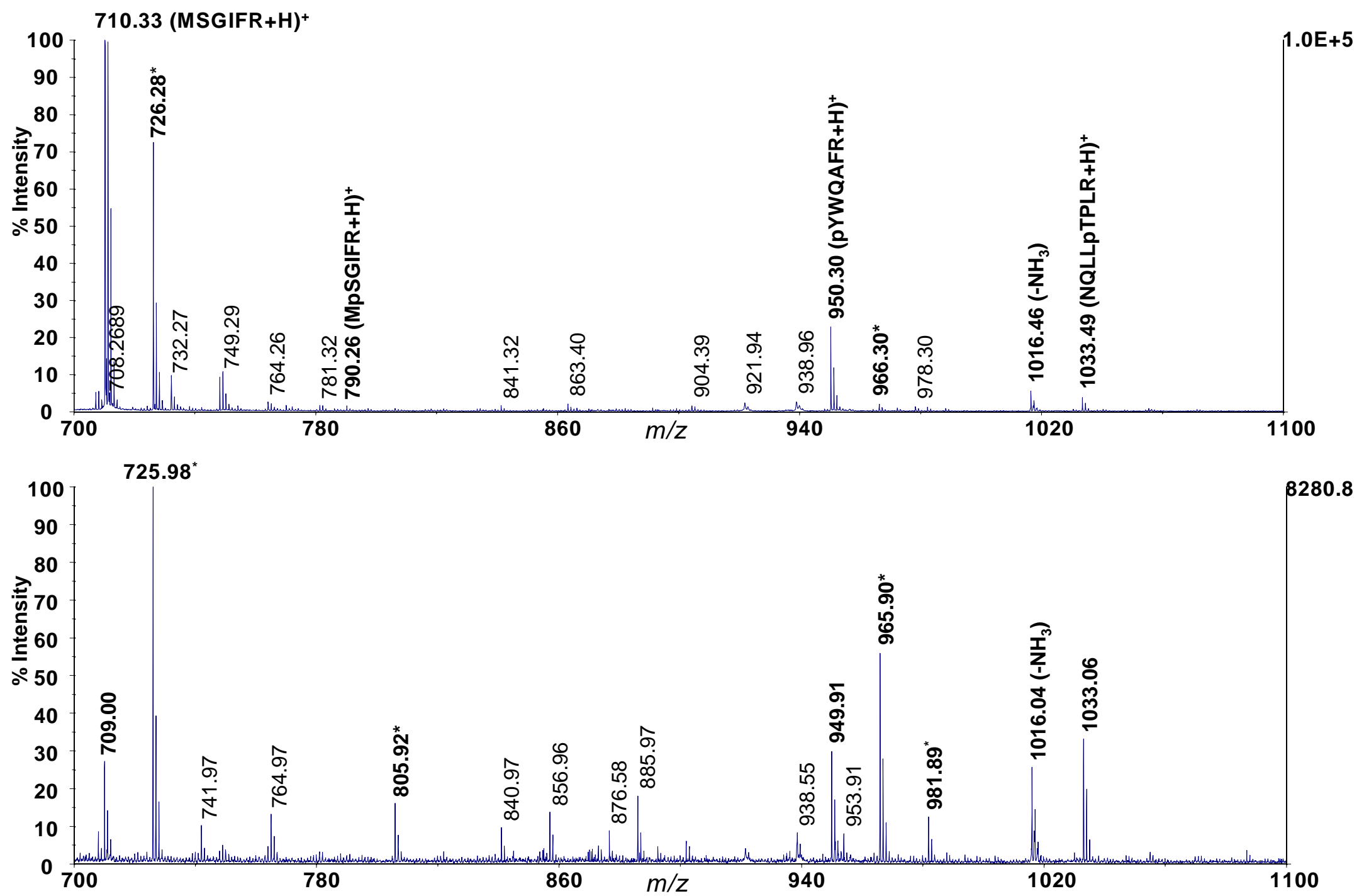

Figure S3. 

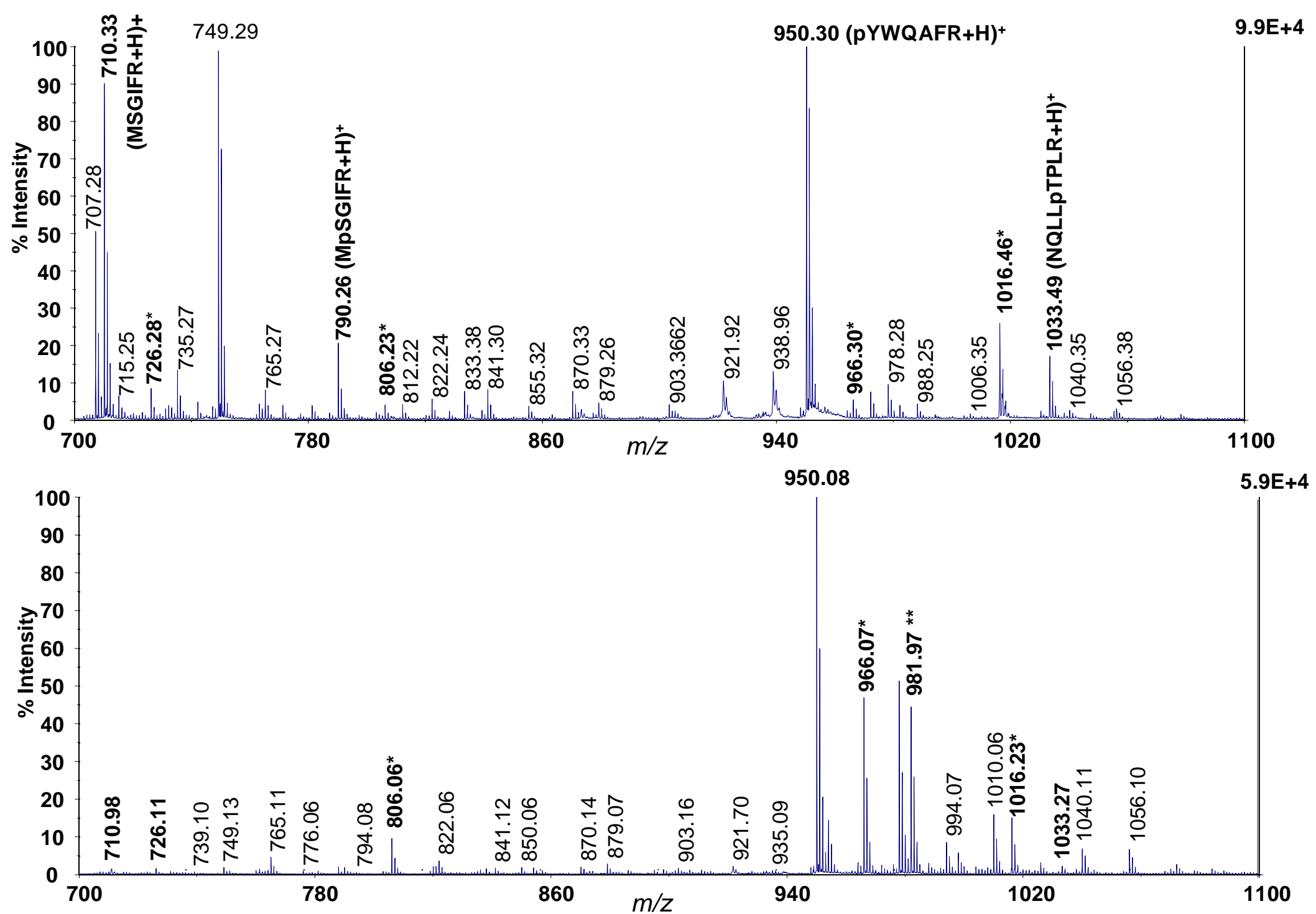

Figure S4. 


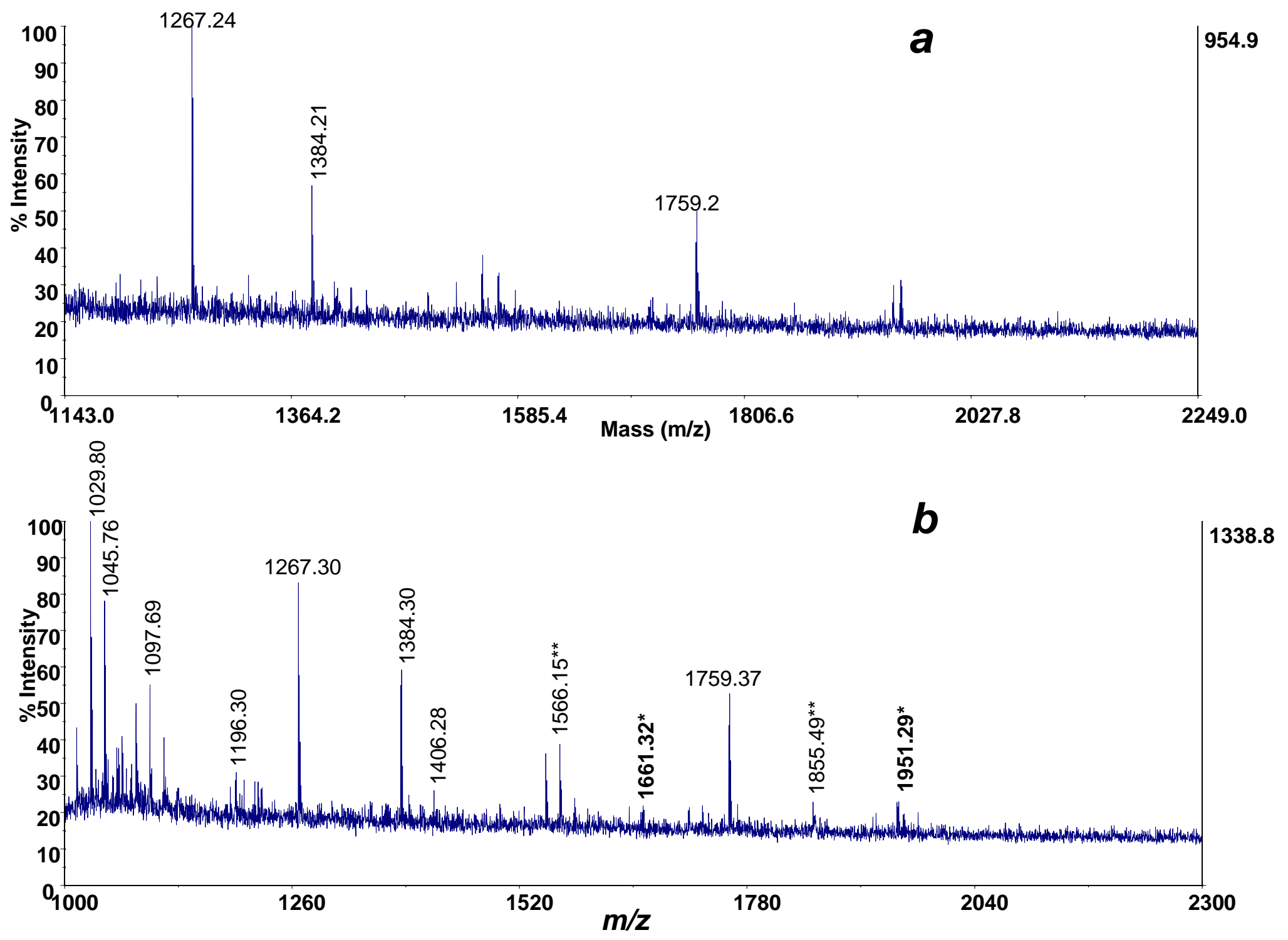

Figure S5. 


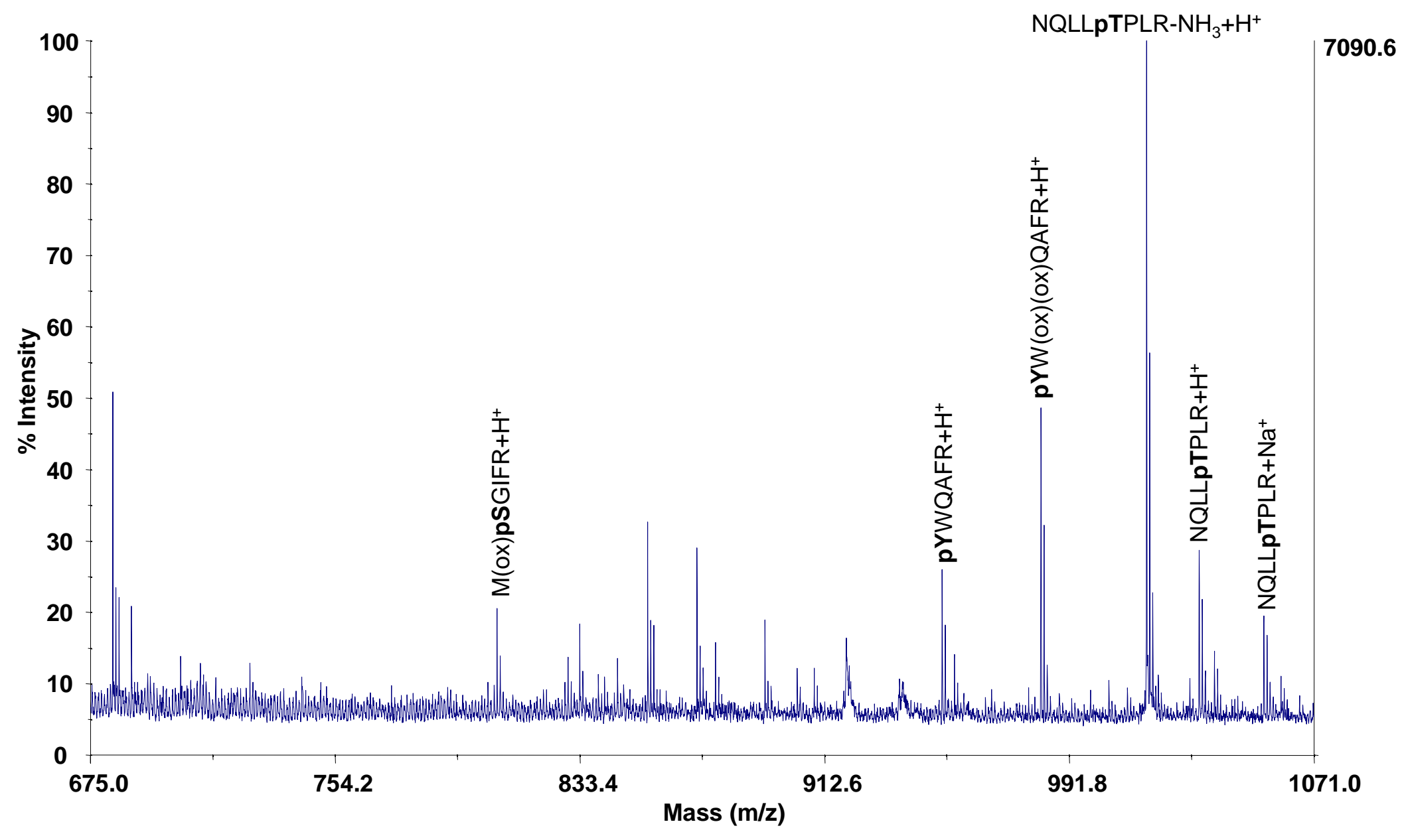

Figure S6. 


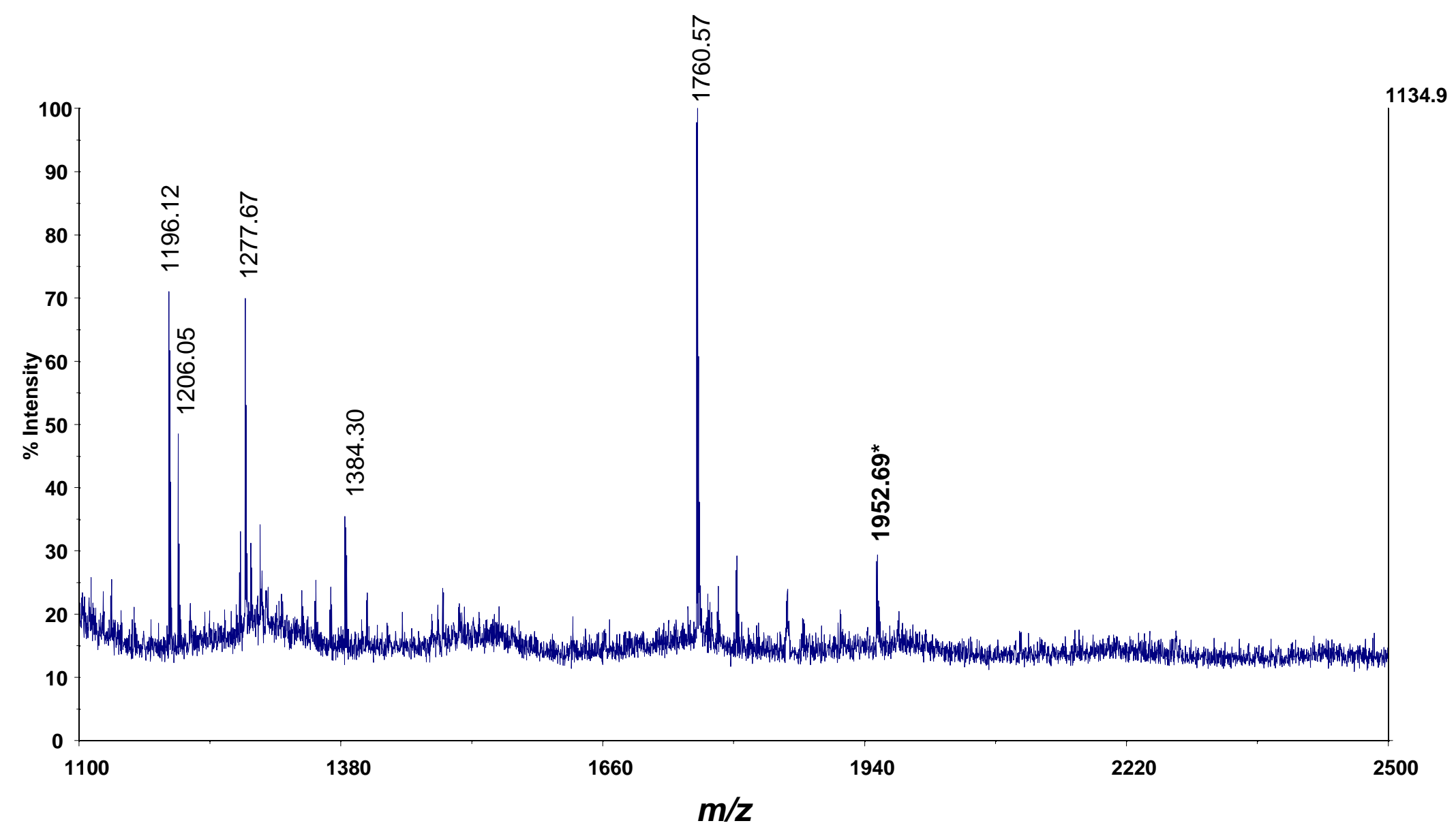

Figure S7. 